\title{
DEVELOPMENT OF MOLECULAR IMPRINTED POLYMER SOLID PHASE EXTRACTION FOR SEPARATION NITROFURANTOIN RESIDUE IN CHICKEN EGGS
}

\author{
SOPHI DAMAYANTI*, UNTUNG GUNAWAN, SLAMET IBRAHIM \\ Department of Pharmacochemistry, School of Pharmacy, Bandung Institute of Technology, Jalan Ganesha, Bandung, Indonesia. \\ Email: sophi.damayanti@fa.itb.ac.id
}

Received: 16 January 2017, Revised and Accepted: 10 March 2017

\begin{abstract}
Objective: The purpose of this study is to obtain molecular imprinted solid phase extraction (MISPE) that is selective for the separation of nitrofurantoin residues in chicken eggs.

Methods: Analytical methods development of nitrofurantoin was optimization of high-performance liquid chromatography (HPLC) system and validation of analytical methods performed to obtain the suitable system for nitrofurantoin detection. In silico study used for MIP design by observing the difference Gibbs free energy using Gaussview 5.08 software with density functional theory methods using 6-311 G as basis set. MIP synthesis was done using bulk method use nitrofurantoin as template, acrylamide as functional monomer, ethylene glycol dimethacrylate as crosslinker, and azobisisobutyronitrile as an initiator reaction inside dimethylformamide (DMF) as a solvent. Non-imprinted polymer (NIP) was synthesized as a comparison. MIP and NIP which has been synthesized was inserted into solid phase extraction (SPE) cartridge and characterized using infrared spectroscopy and HPLC.
\end{abstract}

Result: MISPE that has been synthesized was characterized and compared to NIPsolid phase extraction (NISPE) and marketed SPE $\mathrm{C}_{18}$. The sensitivity of MIP, NIP, and SPE C 18 to nitrofurantoin was $84.54 \%, 37.73 \%$, and 33.95\%, respectively, based on recovery of nitrofurantoin.

Conclusion: Based on the result it was obtained MISPE has high selectivity toward nitrofurantoin compared to NISPE and either marketed SPE.

Keywords: High-performance liquid chromatography, In silico, Molecular imprinted solid phase extraction, Non-imprinted solid phase extraction, Solid phase extraction $\mathrm{C}_{18}$.

(C) 2017 The Authors. Published by Innovare Academic Sciences Pvt Ltd. This is an open access article under the CC BY license (http://creativecommons. org/licenses/by/4. 0/) DOI: http://dx.doi.org/10.22159/ajpcr.2017.v10i6.17109

\section{INTRODUCTION}

Nitrofurantoin (1-[[(5-nitro-2-furanyl) methylene]amino]-2,4imidazolidinedione) is a nitrofuran derivative antibacterial agent used in the therapy of urinary tract infections. It has been in clinical use since 1953 [1]. Escherichia coli was found to be the most common organism responsible for urinary tract infections and it was found to be sensitive to imipenem, nitrofurantoin, amikacin, piperacillin-tazobactam, and gentamicin [2].

The use of antibiotics nitrofuran in food produced from animals is prohibited by the European Union (EU) [3] because of potentially carcinogenic and mutagenic in humans $[4,5]$. In practice, chickens are given antibiotics for either treatment or prophylaxis of infections, and for growth promotion to increase profits [6]. Since 2002, the EU restrictions on imports of poultry products from countries in the Southeast Asia and South America because antibiotics nitrofuran residues have been found in poultry. In some studies, it were found farms used nitrofurantoin for the treatment of infectious diseases in poultry [7]. When nitrofurantoin used for the treatment of fowl, the residues may be existing in chicken eggs $[8,9]$. If the eggs that contain residues of nitrofurantoin are used as a food product, it can be harmful to human's health [5].

Various analysis methods for determination nitrofurantoin residues have been developed, where the most commonly method used is liquid chromatography with mass spectrometry detector (LC-MS) [10,11], but due to the cost of LC-MS that is relatively expensive than another developing method. From the structure of nitrofurantoin that has chromophores, high-performance liquid chromatography using ultraviolet detector (HPLC-UV) could be used to detect the residue of nitrofurantoin in eggs.
Separation technique which usually used for antibiotic residues is solid phase extraction (SPE) and solid phase microextraction (SPME). Selectivity to the analyte is an important requirement to get high recovery from matrices, nowadays molecularly imprinted polymer (MIP) uses for separation of various analytes in a sample for the advantage of more selective compared to SPE and SPME [12]. MIP consists of molecule target, functional monomer, crosslinker, and initiator reaction. Molecule target that used in synthesis MIP is the analyte that will be separated from the matrix. The purpose of this study is to obtain MIP that is selective for the separation of nitrofurantoin residues in chicken eggs.

\section{MATERIALS AND METHODS}

\section{Materials}

The materials used were pro analysis grade unless otherwise stated, nitrofurantoin (Sigma-Aldrich), acrylamide (Merck), methacrylic acid (MAA) (Sigma-Aldrich), hydroxyethyl metacrylate (Sigma-Aldrich), methanol pro HPLC (Merck), acetonitrile pro HPLC (Merck), aqua bidest sterile (Ikapharmindo), potassium dihydrogen phosphate (Merck), dipotassium hydrogen phosphate (Merck), thin-layer chromatography plate silica GF-254, SPE cartridge Chromabond ${ }^{\circledR}$, Waters ${ }^{\circledR}$ SPE Cartridge, chicken eggs.

Software: GaussView 3.08, Gaussian W.03, Minitab 16.

\section{Methods}

There are two main objectives in this research, the first one is to develop and validate an analytical method for determination nitrofurantoin residue, then design and synthesis MIP which selective to nitrofurantoin. Optimization system of HPLC was done using 
one factor at time (OFAT) method. HPLC systems which optimized including composition of the mobile phase, $\mathrm{pH}$ of mobile phase, flow rate, wavelength detection, injection volume, and column temperature. After obtain optimum system HPLC, system suitability test(SST) was done before the measurement of nitrofurantoin released from the MIP.

Computational method was used for designing MIP to observe interaction template with functional monomer and to obtain best functional monomer from in silico design. Template and commonly functional monomer, i.e., acrylamide, MAA, hydroxi-ethylmetacrilate, allyl alcohol, acrylic acid, itaconic acid, methacrylamide, p-vinil benzoat, and vinilglisin were drawn using Gaussview 5.08 software. Geometry optimization was performed by density functional theory method with basis set 6-311 G. Predictions complexes were formed by hydrogen bonds between monomer and each observed monomer to gain Gibbs free energy. The Gibbs free energy gains of the complexes were calculated using the equation:

\section{$\Delta \mathrm{G}=\mathrm{G}$ template-monomer complex $-\mid \mathrm{G}$ template $+\mathrm{G}$ monomer $\mid$}

Where $\Delta$ Gis the change in Gibbs free energy on the formation of template-monomer complex, $\mathrm{G}$ template-monomer complex is the Gibbs free energy of template-monomer complex, G template is the Gibbs free energy of template, and G monomer is the Gibbs free energy of monomer molecules.

Best monomer from in silico design was characterized using UV titration to obtain interaction between template and monomer functional and determine association constants of template-monomer complex. MIP synthesis was done using the bulk method, where template, functional monomer, crosslinker, and initiator reaction dissolved in a solvent followed by heating. Optimization of synthesis performed using OFAT method by optimizing the composition of template, functional monomer, crosslinker, initiator, temperature reaction, and reaction time.

Non-imprinted polymer (NIP) was prepared with the same composition and method of the MIP as a comparison of MIP. Template removal from MIP was done by optimization of some methods, i.e., sonication, Soxhlet, and reflux, infrared spectroscopy (IR) used for analysis MIP and NIP. MIP which has been free from the template was characterized to determine adsorption capacity of MIP. Preparation molecular imprinted SPE (MISPE) was done by insertion of MIP into SPE cartridge. Separation of nitrofurantoin using MISPE was similar as SPE separation, the methods including conditioning MISPE, sample insertion, washing of matrices, and analyte elution. The methods were optimized to get high recovery of nitrofurantoin.

Test of the performance MISPE was done by comparing the release of nitrofurantoin in MISPE synthesized, non-imprinted SPE (NISPE) and commercially available SPE $\mathrm{C}_{18}$. About $1 \mu \mathrm{g} / \mathrm{ml}$ of nitrofurantoin was added to 1 gram egg sample then mixed, then $1 \mathrm{ml}$ acetonitrile was added to precipitate protein, acetonitrile phase was then inserted into MISPE, eluted with $1 \mathrm{ml}$ DMF. DMF resulted was collected and injected into HPLC system.

\section{RESULTS}

Analytical method validation performed by testing specificity, linearity, limit of detection (LOD) and limit of quantification (LOQ), accuracy, precision, and robustness of method.

LOD and LOQ were calculated by Miller and Miller equation with LOD = $1.199 \mu \mathrm{g} / \mathrm{ml}$, and LOQ $=3.634 \mu \mathrm{g} / \mathrm{ml}$.

After analytical method validated, in silico study was done to find the suitable monomer to interact with nitrofurantoin, the monomer was selected from Gibbs free energy value by observe interaction between nitrofurantoin with the usual monomer used in MIP synthesis.
UV titration used to obtain interaction between template and monomer functional.

Determination of association constants of template-monomer complex was calculated using formula [11]:

$$
\Delta \lambda=\frac{\mathrm{K}[\mathrm{M}]}{1+\mathrm{K}[\mathrm{M}]}-\Delta \lambda \max
$$

$\Delta \lambda=$ Wavelength differences,

$\mathrm{K}=$ association constants,

$[\mathrm{M}]=$ monomer concentration (Molor),

$\Delta \lambda \max =$ maximum wavelength difference.

Association constants of acrylamide-nitrofurantoin were $-1.15625 \times 10^{4} \mathrm{M}^{-1}$

MIP and NIP were characterized using IR spectroscopy, optimization method for extract template from MIP was done. Binding capacity MIP and NIP was compared using optimized HPLC system. MISPE and NISPE were examined using egg samples which added with nitrofurantoin.

From the research, we can also observed the imprinting factor, where,

$$
\mathrm{IF}=\frac{\mathrm{K}_{\mathrm{D}} \text { MISPE }}{\mathrm{K}_{\mathrm{D}} \text { NISPE }}
$$

IF=Imprinting factor,

$\mathrm{K}_{\mathrm{D}}=$ Distribution coefficient

Imprinting factor value of MISPE which has been synthesized was 2.241 .

\section{DISCUSSION}

Optimization of HPLC system was done using OFAT method, the optimum system for analysis nitrofurantoin using HPLC (Table 1), SST in Table 2 provided that optimized system work correctly to analysis nitrofurantoin, analytical method validation including specificity, linearity, accuracy, precision, LOD, LOQ and robustness of method (Fig. 1, Tables 3 and 4) [13].

In silico study using Gaussview 5:08 software showed that MAA is the best monomer which reacts with nitrofurantoin (Table 5). The Gibbs free energy, lower energy showed strong interaction between monomer and template which usually formed from hydrogen bonding [12]. In the step of synthesis, no polymer was obtained which probably caused by dimer formation of methacrylic acid. The acrylic derivative monomer usually formed dimer, therefore the hydrogen bonding was not occurred [14]. Acrylamide was selected as monomer for synthesis MIP because

\section{Table 1: Optimum condition of HPLC system}

\begin{tabular}{ll}
\hline Column & Lichosphere R100 ${ }^{\circledR}, \mathrm{C}_{18} \mathrm{RP}, 5 \mu \mathrm{m}$ \\
Detector & $\mathrm{UV} 365 \mathrm{~nm}$ \\
Mobile phase & Acetonitrile: Phospate buffer pH 4 (20:80) \\
Flow rate & $1.5 \mathrm{ml} /$ minutes \\
Column temperature & $25^{\circ} \mathrm{C}$ \\
Injection volume & $20 \mu \mathrm{l}$ \\
\hline HPLC: High-performance liquid chromatography, UV: Ultraviolet
\end{tabular}

Table 2: SST result

\begin{tabular}{ll}
\hline Parameter & Value \\
\hline Capacity factor & 2.072 \\
Injection repeatability & $1.240 \%$ \\
Relative retention & - \\
Resolution & - \\
Tailing factor & 0.990 \\
Theoretical plate number $\left(/ \mathrm{m}^{2}\right)$ & 9500 \\
\hline SST: System suitability test &
\end{tabular}


Table 3: Recovery value of nitrofurantoin

\begin{tabular}{lll}
\hline Concentration (\%) & Replication & Recovery (\%) \\
\hline 80 & 1 & 99.36 \\
& 2 & 100.95 \\
& 3 & 100.17 \\
100 & 1 & 100.07 \\
& 2 & 100.21 \\
\multirow{2}{*}{120} & 3 & 100.69 \\
& 1 & 98.98 \\
& 2 & 99.63 \\
& 3 & 99.47 \\
\hline
\end{tabular}

Table 4: Value of precision (coefficient of variant, \%)

\begin{tabular}{llll}
\hline Variable & Day 1 & Day 2 & Day 3 \\
\hline Coefficient of variance & 0.4650 & 0.7543 & 0.6954 \\
\hline
\end{tabular}

Table 5: Gibbs free energy value

\begin{tabular}{ll}
\hline Monomer & $\boldsymbol{\Delta G}$ reaction $(\mathbf{k c a l} / \mathbf{m o l})$ \\
\hline Acrylamide & -3098.55 \\
MAA & -3846.55 \\
HEMA & -1923.14 \\
Allyl alcohol & -1212.05 \\
Acrylic acid & -1427.61 \\
p-vinylbenzoic acid & -3126.39 \\
\hline
\end{tabular}

MAA: Methacrylic acid, HEMA: Hydroxyethyl methacrylate

Table 6: UV titration of acrylamide-nitrofurantoin

\begin{tabular}{lll}
\hline Nitrofurantoin:acrylamide & Wavelength (nm) & Absorbance \\
\hline $1: 0$ & 361 & 1.8001 \\
$1: 1$ & 363 & 1.6037 \\
$1: 2$ & 364 & 1.4856 \\
$1: 3$ & 365 & 1.3756 \\
$1: 4$ & 365 & 1.2492 \\
$1: 5$ & 365 & 1.1540 \\
$1: 6$ & 364 & 1.1034 \\
$1: 7$ & 364 & 1.0227 \\
$1: 8$ & 365 & 0.9878 \\
$1: 9$ & 365 & 0.9386 \\
$1: 10$ & 364 & 0.8976 \\
\hline
\end{tabular}

UV: Ultraviolet

Table 7: Binding of MIP and NIP to nitrofurantoin

\begin{tabular}{lll}
\hline Substances & AUC & Nitrofurantoin binding (\%) \\
\hline Standard $(1 \mu \mathrm{g} / \mathrm{mL})$ & 310.50 & - \\
NIP & 77.625 & 24.99 \\
MIP & 149.00 & 47.98
\end{tabular}

NIP: Non-imprinted polymer, MIP: Molecular imprinted polymer, AUC: Area under the curve

Table 8: Recovery value of MISPE and NISPE

\begin{tabular}{lll}
\hline Substances & AUC & Recovery (\%) \\
\hline Standard $(1 \mu \mathrm{g} / \mathrm{mL})$ & 310.50 & - \\
MISPE & 263.44 & 84.54 \\
NISPE & 117.15 & 37.73 \\
C-18 & 105.44 & 33.95 \\
\hline
\end{tabular}

MISPE: Molecular imprinted polymer solid phase extraction,

NISPE: Non-imprinted polymer solid phase extraction, AUC: Area under the curve acrylamide has the second lowest Gibbs free energy from in silico design (Table 5). Interaction from acrylamide with nitrofurantoin was observed from UV titration which shows in table (Table 6 and Fig. 2). Acrylamide interacts with nitrofurantoin in a minimum ratio of $3: 1$ with the association constant of $-1.15625 \times 10^{4} \mathrm{M}^{-1}$.

MIP was synthesized using a bulk method where template, functional monomer, crosslinker, and initiator reaction was dissolved in porogen solvent then the reaction is initiated by heating, from optimization ratio template-monomer-crosslinker $(1: 4: 20)$ was optimized formula for synthesis MIP. NIP synthesized using same method and ratio for MIP comparison [15] after synthesized MIP and NIP were analyzed using Fourier transform IR, the result shown in Figs. 3 and 4.

Method to remove the template from MIP including sonication, Soxhlet and reflux method were optimized, Soxhlet method with dimethylformamide (DMF) as a solvent was the best method to remove nitrofurantoin from MIP, the comparison MIP which has been Soxhlet with DMF and NIP show in Fig. 5, the spectrum shows similar peak which gives information that template removal work properly [16].

MIP that has been extracted was characterized to observe the adsorption capacity of MIP to bind nitrofurantoin, adsorption capacity was determined using the batch method and analyzed by HPLC which already optimized and validated, adsorption capacity MIP was $47.98 \%$ (Table 7).

MISPE prepared by insert MIP into SPE cartridge Chromabond ${ }^{\circledR}$, NISPE was prepared for MISPE comparison. MISPE used for nitrofurantoin separation in chicken eggs matrices. Conditioning, washing and

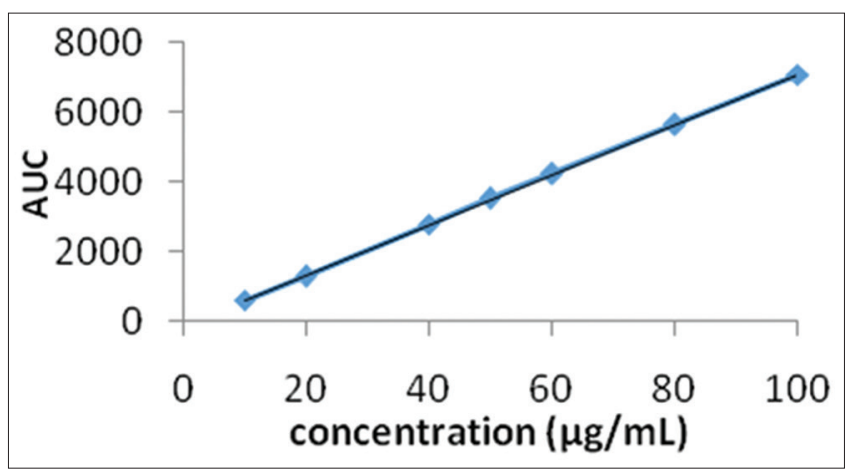

Fig. 1: Calibration curve, $y=72.168 x-113.63, r^{2}=0.999$, Vxo=0.707\%

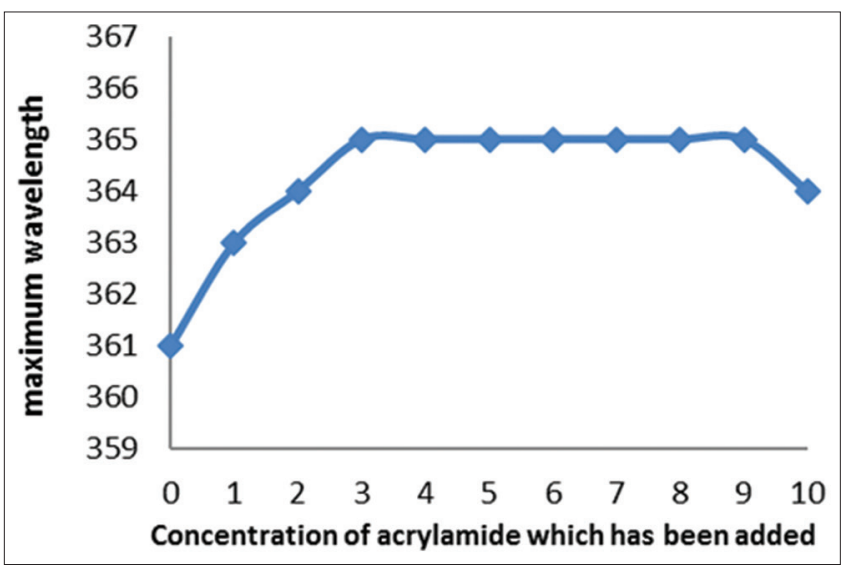

Fig. 2: Interaction curve between acrylamide with nitrofurantoin 


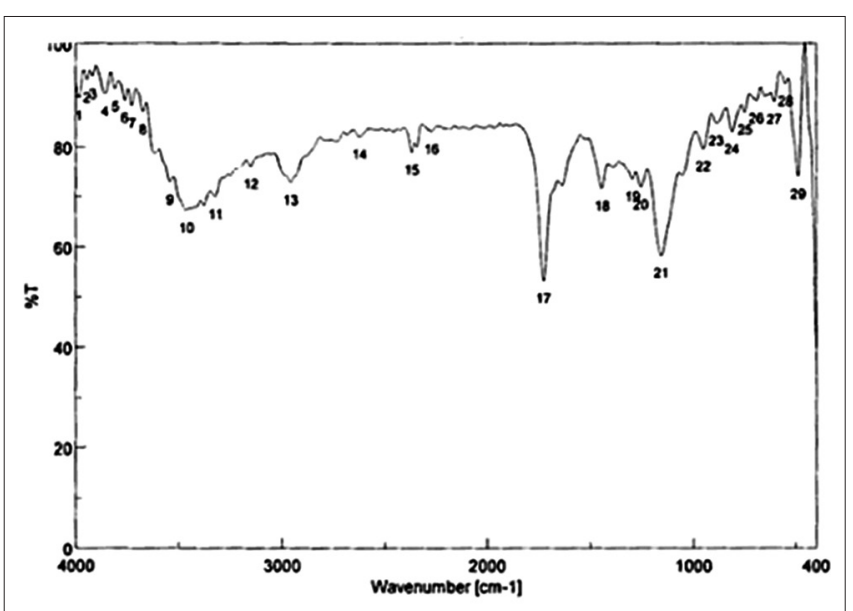

Fig. 3: Infrared spectrum of molecularly imprinted polymer

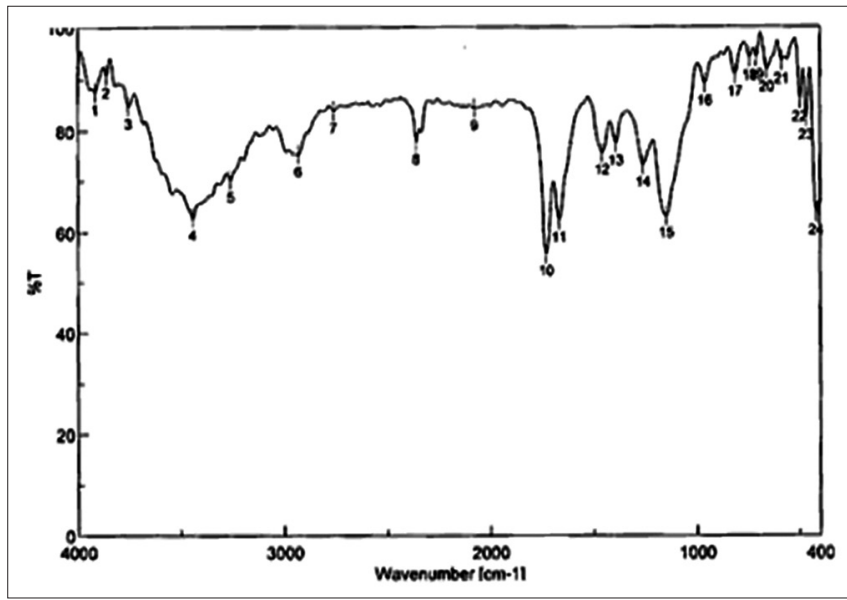

Fig. 4: Infrared spectrum of non-imprinted polymer

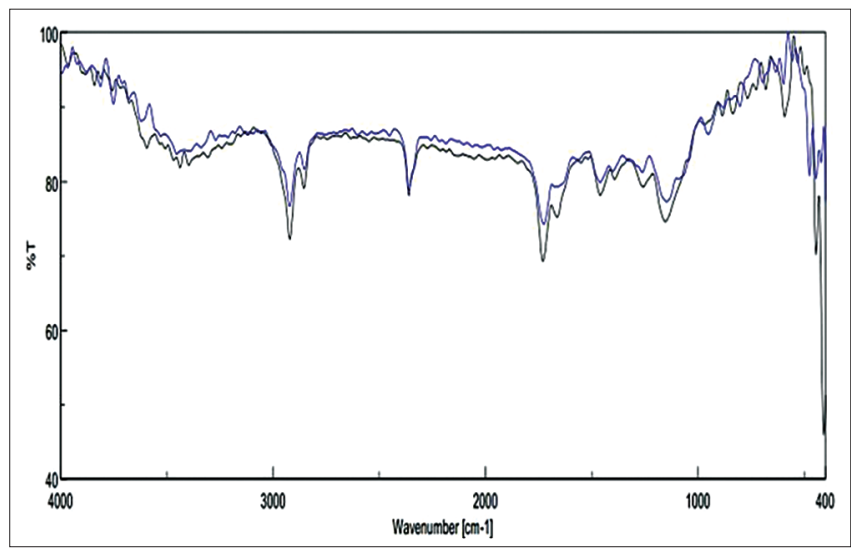

Fig. 5: Overlay spectrum between non-imprinted polymer (NIP) with molecular imprinted polymer (MIP) which has been extracted by dimethylformamide (blue=MIP, black=NIP)

eluting optimization was done same as separation using SPE [17], from optimization methanol used for conditioning MISPE, then sample inserted into MISPE, washing sample was not done to prevent loss of analyte, and DMF used for the eluting analyte, then DMF phase analyzed using validated HPLC system.

To test the performance of MISPE, synthesis MISPE compared with NISPE and SPE $\mathrm{C}_{18}$ on the market to analysis nitrofurantoin in chicken eggs (Table 8), the recovery of nitrofurantoin which separated by MISPE, NISPE, and $\mathrm{C}_{18}$ on the market in a row was $84.54 \%, 37.73 \%$, and $33.95 \%$, respectively.

\section{CONCLUSION}

Analytical method development of nitrofurantoin analysis using HPLC resulted in a valid method. MISPE was selective to nitrofurantoin and showed higher sensitivity in comparison to NISPE and SPE $\mathrm{C}_{18}$ on the market.

\section{ACKNOWLEDGMENTS}

The authors gratefully acknowledge financial support by Ministry of Finance Indonesia through Indonesia Endowment Fund for Education (LPDP).

\section{REFERENCES}

1. Muth P, Metz R, Siems B, Bolten WW, Vergin H. Sensitive determination of nitrofurantoin in human plasma and urine by high-performance liquid chromatography. J Chromatogr A 1996;729(1-2):251-8.

2. Jain S, Walia G, Malhotra R. Prevalence and antimicrobial susceptibility of ESBL producing gram negative bacilli in 200 cases of urinary tract infections. Int J Pharm Pharm Sci 2014;6(10):210-1.

3. Commission Regulation (EC), 1442/95. Procedure for the establishment of maximum residue limits of veterinary medicinal products in foodstuffs of animal origin. Official J Eur Communities 1995;L143:26-30.

4. Van Koten JE, Wouters MF, Van Leeuwen FX. Report of the $40^{\text {th }}$ Meeting of the Joint FAO/WHO Expert Committee on Food Additives (JECFA). Geneva: WHO; 1993. p. 85-123.

5. Morris JE, Price JM, Lalich JJ, Stein RJ. The carcinogenic activity of some 5-nitrofuran derivatives in the rat. Cancer Res 1969;29(12):2145-56.

6. Mwabete KD, Stephen WS. Antimicrobial resistance profiles of bacteria isolated from chicken droppings in dar es salaam. Int J Pharm Pharm Sci 2015;7(9):268-71.

7. Damerow G. The Chicken Health Handbook. New York: Versa Press; 1994.

8. Cooper KM, Mccracken RJ, Buurman M, Kennedy DG. Residues of nitrofuran antibiotic parent compounds and metabolites in eyes of broiler chickens. Food Addit Contam 2008;25(5):526-48.

9. Mccracken RJ, Van Rhijn JA, Kennedy DG. Transfer of nitrofuran residues from parent broiler breeder chickens to broiler progeny. $\mathrm{Br}$ Poult Sci 2005;46(3):87-292.

10. Kumar L, Toothill JR, Ho KB. Determination of nitrofuran residues in poultry muscle tissues and eggs by liquid chromatography. J AOAC Int 1994;77(3):591-5

11. Dinesh SP, Naveen S, Mukesh CP, Bhavin NP, Pranav SS, Mallika S. Quantitation of nitrofurantoin in human plasmaby liquid chromatography tandem mass spectrometry. Acta Pharm 2013;63:141-58.

12. Lorenzo CA, Concheiro A. Handbook of Molecularly Imprinted Polymer. United Kingdom: Smithers Rapra; 2013.

13. Harmita. Petunjuk pelaksanaan validasi metode dan Cara Perhitungannya (Guideline and practical approach of analytical method validation). Majalah Ilmu Kefarmasian 2004; 1(3): 117-135.

14. Haupt K. Molecularly imprinted polymers in analytical chemistry. Analyst 2001;126(6):747-56.

15. Vasapollo G, Del Sole R, Mergola L, Lazzoi MR, Scardino A, Scorrano S, et al. Molecularly imprinted polymers: Present and future prospective. Int J Mol Sci 2011;12:5909-32.

16. Yan H, Row HK. Characteristic and synthetic approach of molecularly imprinted polymer. Int J Mol Sci 2006;7:156-75.

17. Simpson NJ. Solid-Phase Extraction: Principles, Techniques, and Applications. California: Marcel Dekker; 2000. 